Supporting Information (SI)

\title{
Modulator-Induced Zr-MOFs Diversification and Investigation of Their Properties in Gas Sorption and $\mathrm{Fe}^{3+}$ Ion Sensing
} Jun-Hao Wang, *a Meng-Na Li, a, b Shu Yan, ${ }^{\text {a, b }}$ Ying Zhang, ${ }^{\mathrm{b}}$ CongCong Liang, ${ }^{\mathrm{c}}$ Xian-Ming Zhang, *a, d and Yue-Biao Zhang ${ }^{\mathrm{c}}$

a. Institute of Crystalline Materials, Shanxi University, Taiyuan 030006 (China).

b. Institute of Molecular Science, Shanxi University, Taiyuan 030006 (China).

c. School of Physical Science and Technology, Shanghai Tech University, Shanghai 201210 (China)

d. School of Chemistry and Material Science, Shanxi Normal University, Linfen 041004 (China).

E-mail:jhwang@sxu.edu.cn; zhangxm@dns.sxnu.edu.cn.

\section{Table of Contents}

Experimental Section S2-S3

Materials and physical measurements; Syntheses of Zr-SXU-1 3 and activation of MOFs

Crystal Data Section S4-S11

Fig. S1, S2, S3, S4, S5, S6 (Crystal structure analysis of Zr-SXU-1 3); Table S1

Gas Sorption measurement .S11-S15

Fig. S7, S8, S 9; Table S2 S4

Fluorescence Measurement S15-S16

Fig. S10, Fig. S11, Fig. S12, Fig. S13 


\section{Experimental Section}

\section{Materials and physical measurements:}

PBPTTBA (4, 4', 4", 4"”-(1, 4-phenylenebis(pyridine-4, 2, 6-triyl))tetrabenzoic acid) was prepared according to reported procedure (Angew. Chem. Int. Ed., 2017, 56, 6478-6482). Other reagents and solvents were commercially available and used without further purification. Powder X-ray diffraction (PXRD) experiments were performed on a Rigaku Ultimate IV diffractometer. Thermogravimetric (TG) analysis was performed on a Setaram labsys evo Thermogravimetric Analyzer under nitrogen flow $\left(30 \mathrm{~mL} \cdot \mathrm{min}^{-1}\right)$ at a typical heating rate of $5{ }^{\circ} \mathrm{C} \cdot \mathrm{min}^{-1} .{ }^{1} \mathrm{H}$ NMR spectra were recorded on a Bruker AVANCE III spectrometer using the TMS as internal standard. All $\delta$ values are given in ppm. The diffuse reflectance ultraviolet-visible (DR UV-vis) spectra were measured with a PeRsee TU-1950 UV-Vis spectrophotometer. Fluorescence measurements were carried out on a FLS980 Luminescence Spectrometer equipped with a continuous Xe900 Xenon lamp and a red-sensitive Peltier-cooled Hamamatsu R928P photomultiplier tube (PMT) at room temperature. Gas adsorption isotherms were measured on the Quantachrome autosorb iQ2 automated gas sorption analyzer. The as-synthesized samples were activated at $150^{\circ} \mathrm{C}$ for 12 hours by using the "outgas" function of the surface area analyzer before measurements.

\section{Synthesis}

\section{Synthesis of Zr-SXU-1}

Single crystals: $\mathrm{ZrOCl}_{2} \bullet 8 \mathrm{H}_{2} \mathrm{O}(0.0064 \mathrm{~g}, 0.02 \mathrm{mmol})$ and benzoic acid $(0.2687 \mathrm{~g}, 2.2 \mathrm{mmol})$ were dissolved in $1.5 \mathrm{~mL}$ DMF and ultrasonically dissolved. The clear solution was heated in an oven at $80{ }^{\circ} \mathrm{C}$ for 1 hour. After cooling down to room temperature, $0.5 \mathrm{~mL}$ of DMF solution with PBPTTBA $(0.0057 \mathrm{~g}, 0.008 \mathrm{mmol})$ were added to this solution and the mixture was heated in an oven at $120{ }^{\circ} \mathrm{C}$ for $48 \mathrm{~h}$. After cooling down to room temperature, prismatic colorless crystals were collected by centrifugation and washed with fresh DMF and acetone several times.

Powders: PBPTTBA $(0.007 \mathrm{~g}, 0.01 \mathrm{mmol}), \mathrm{ZrOCl}_{2} \bullet 8 \mathrm{H}_{2} \mathrm{O}(0.0107 \mathrm{~g}, 0.03 \mathrm{mmol})$ and acetic acid $(0.6 \mathrm{ml})$ were dissolved in $2.5 \mathrm{~mL}$ DMF. The mixture was heated in oven at $120^{\circ} \mathrm{C}$ for 48 hours to afford a white precipitate which was collected by centrifugation and washed with fresh DMF and acetone several times.

\section{Synthesis of Zr-SXU-2}


Single crystals: $\mathrm{ZrOCl}_{2} \bullet 8 \mathrm{H}_{2} \mathrm{O}(0.0064 \mathrm{~g}, 0.02 \mathrm{mmol})$ and benzoic acid $(0.5129 \mathrm{~g}, 4.2 \mathrm{mmol})$ were dissolved in $2 \mathrm{~mL}$ DMF and ultrasonically dissolved. The clear solution was incubated in an oven at $80{ }^{\circ} \mathrm{C}$ for 1 hour. After cooling down to room temperature, $1 \mathrm{~mL}$ of DMF solution with PBPTTBA $(0.007 \mathrm{~g}, 0.01 \mathrm{mmol})$ and DMTPDC $(0.0035 \mathrm{~g}, 0.01 \mathrm{mmol})$ was added to this solution and the mixture was heated in an oven at $120{ }^{\circ} \mathrm{C}$ for $48 \mathrm{~h}$. After cooling down to room temperature, cubic colorless crystals were collected by centrifugation and washed with fresh DMF and acetone several times.

Powders: $\mathrm{ZrOCl}_{2} \bullet 8 \mathrm{H}_{2} \mathrm{O}(0.0064 \mathrm{~g}, 0.02 \mathrm{mmol})$ and benzoic acid $(0.3663 \mathrm{~g}, 3 \mathrm{mmol})$ were dissolved in $2 \mathrm{~mL}$ DMF and ultrasonically dissolved. The clear solution was incubated in an oven at $80{ }^{\circ} \mathrm{C}$ for $1 \mathrm{~h}$. After cooling down to room temperature, $1 \mathrm{~mL}$ of DMF solution with PBPTTBA $(0.007 \mathrm{~g}, 0.01 \mathrm{mmol})$ and DMTPDC $(0.0035 \mathrm{~g}, 0.01 \mathrm{mmol})$ was added to this solution and the mixture was heated in an oven at $120{ }^{\circ} \mathrm{C}$ for $48 \mathrm{~h}$. After cooling down to room temperature, white precipitate was collected by centrifugation and washed with fresh DMF and acetone several times.

\section{Synthesis of Zr-SXU-3}

Single crystals: $\mathrm{ZrOCl}_{2} \bullet 8 \mathrm{H}_{2} \mathrm{O}(0.0129 \mathrm{~g}, 0.04 \mathrm{mmol})$ and benzoic acid $(0.6839 \mathrm{~g}, 5.6 \mathrm{mmol})$ were dissolved in $1.5 \mathrm{~mL}$ DMF and ultrasonically dissolved. The clear solution was incubated in an oven at $80{ }^{\circ} \mathrm{C}$ for 1 hour. After cooling down to room temperature, $0.5 \mathrm{~mL}$ of DMF solution with PBPTTBA $(0.01425 \mathrm{~g}, 0.02 \mathrm{mmol})$ was added to this solution and the mixture was heated in an oven at $120{ }^{\circ} \mathrm{C}$ for $48 \mathrm{~h}$. After cooling down to room temperature, block colorless crystals were collected by centrifugation and washed with fresh DMF and acetone several times.

Powders: $\mathrm{ZrCl}_{4}(0.309 \mathrm{~g}, 1.33 \mathrm{mmol})$, benzoic acid $(9.60 \mathrm{~g}, 78.5 \mathrm{mmol})$ and PBPTTBA $(0.220$ $\mathrm{g}, 0.31 \mathrm{mmol}$ ) were dissolved in $45 \mathrm{~mL}$ DMF and heat reflux for $48 \mathrm{~h}$. After cooling down to room temperature, white precipitates was collected by centrifugation and washed with fresh DMF and acetone several times.

\section{Activation of MOFs}

Activation procedure for Zr-SXU-1、Zr-SXU-2 and Zr-SXU-3: $100 \mathrm{mg}$ of these materials were dispersed in $10 \mathrm{~mL}$ DMF at $80{ }^{\circ} \mathrm{C}$ for five times with DMF refreshed for every 2 hours and then solvent exchanged to $\mathrm{CH}_{2} \mathrm{Cl}_{2}(8 \times 10 \mathrm{~mL})$ before thermally activating these materials at $80{ }^{\circ} \mathrm{C}$ for $12 \mathrm{~h}$ under dynamic vacuum. 


\section{Crystal Data Section}

Single crystal data collection of Zr-SXU-1 and Zr-SXU-2 were performed on BL17B1 in Shanghai Synchrotron Radiation Facility (SSRF) at 100 K. Single crystal data collection of Zr-SXU3 was performed on Rigaku oxford Xcalibur single-crystal X-ray diffractometer equipped with a $\mathrm{CCD}$ area detector and operated at $40 \mathrm{kV}, 40 \mathrm{~mA}$ to generate $\mathrm{Mo} \mathrm{K} \alpha$ radiation $(\lambda=0.71073 \AA)$ at room temperature (298 K). The data of Zr-SXU-3 was processed using CrysAlis RED, Oxford Diffraction Ltd and the structure was solved by ShelXT methods in Olex2 software and refined on F2 using full-matrix last-squares (ShelXL-2013). All non-hydrogen atoms were refined with anisotropic thermal parameters, and all hydrogen atoms were included in calculated positions and refined with isotropic thermal parameters riding on those of the parent atoms. The treatment for the guest molecules in Zr-SXU-1 and Zr-SXU-2 involved the use of the SQUEEZE program of PLATON. The data of Zr-SXU-2 was very poor due to its small size and very weak diffraction. We can only determine the exact position of the $\mathrm{Zr}-\mathrm{O}$ clusters. By using these data, the structure of $\mathrm{Zr}$ SXU-2 was further build from Materials Studio and was optimized by Forcite calculation (Smart Algorithm with ultra-fine quality). Parameters for data collection and refinement of Zr-SXU-1 and Zr-SXU-3 are summarized in Table S1.

\section{Crystal structure analysis of Zr-SXU-1}
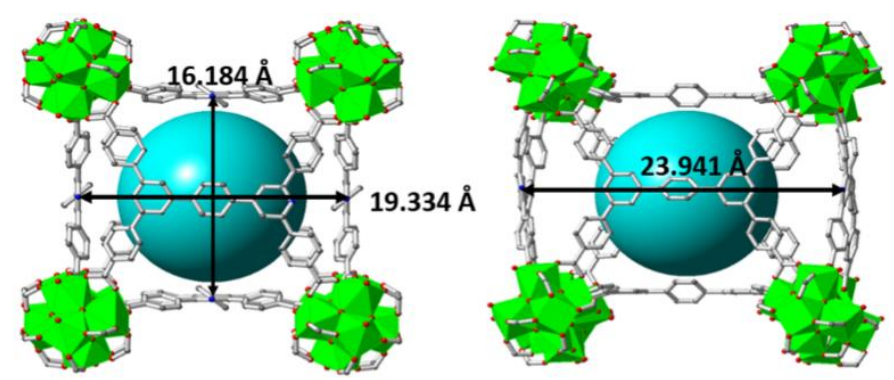

(a)
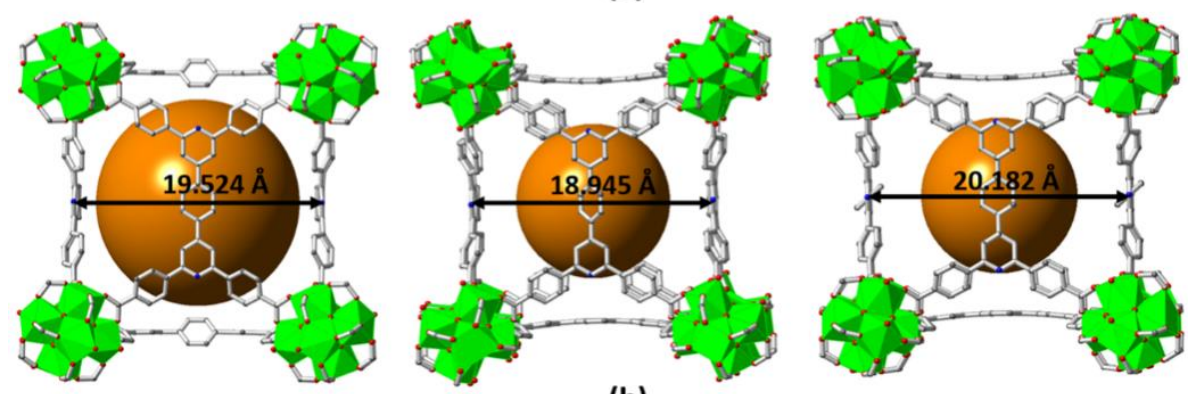

(b) 


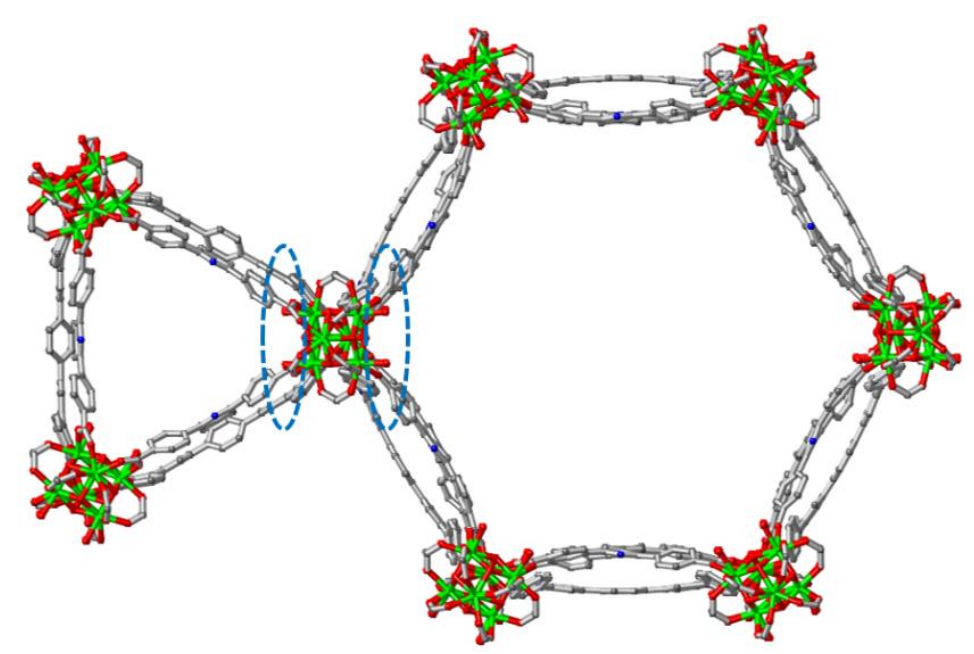

(c)

Figure S1. (a) The sizes of the rectangular prism cages, (b) The sizes of the quasi-cubic cages and (c) the terminal hydroxyl/water groups which point to the wall of the hexagonal and trigonal channels.
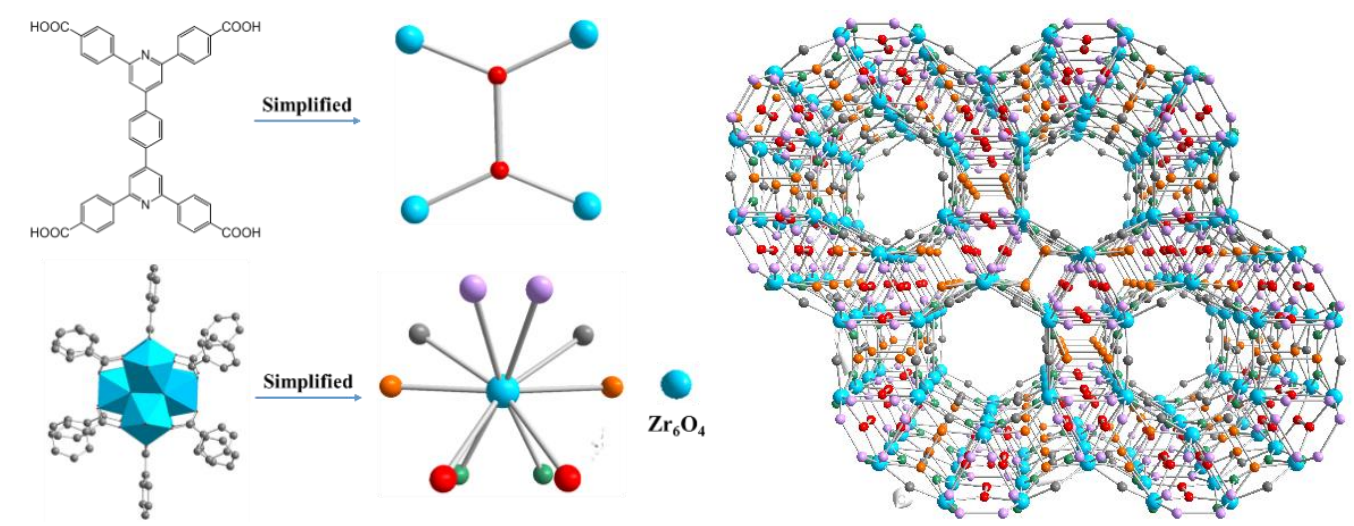

Figure S2. Topological simplification of Zr-SXU-1.

\section{The topological results of $\mathrm{Zr}-\mathrm{SXU}-1$ calculated by ToposPro 5.0}

Coordination sequences

$\mathrm{C} 1: \begin{array}{llllllllll}1 & 2 & 3 & 4 & 5 & 6 & 7 & 8 & 9 & 10\end{array}$

Num $32033 \quad 64110156232320 \quad 391 \quad 485$

Cum 4245712123138761993913301815

$\begin{array}{lllllllllll}\mathrm{C} 2: & 1 & 2 & 3 & 4 & 5 & 6 & 7 & 8 & 9 & 10\end{array}$

Num $31936 \quad 70124158251336 \quad 390 \quad 504$

Cum 4235912925341166299813881892

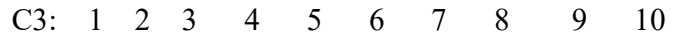

Num $31934 \quad 67114155237321 \quad 392 \quad 502$

Cum 4235712423839363095113431845

C4: $\begin{array}{llllllllll}1 & 2 & 3 & 4 & 5 & 6 & 7 & 8 & 9 & 10\end{array}$ 
Num $31934 \quad 72122165236331 \quad 409 \quad 508$

Cum 4235712925141665298313921900

C5: $\begin{array}{llllllllll}1 & 2 & 3 & 4 & 5 & 6 & 7 & 8 & 9 & 10\end{array}$

Num $31934 \quad 74122167234328 \quad 410 \quad 513$

Cum 4235713125342065498213921905

C6: $\begin{array}{lllllllllll}1 & 2 & 3 & 4 & 5 & 6 & 7 & 8 & 9 & 10\end{array}$

Num $101649 \quad 84110191263 \quad 317 \quad 440 \quad 545$

Cum 112776160270461724104114812026

$\mathrm{TD} 10=1897$

Vertex symbols for selected sublattice

C1 Point symbol: $\left\{5^{\wedge} 3\right\}$

Extended point symbol:[5(2).5(2).5(2)]

C2 Point symbol: $\left\{4.5^{\wedge} 2\right\}$

Extended point symbol:[4.5.5]

C3 Point symbol: $\left\{4.5^{\wedge} 2\right\}$

Extended point symbol:[4.5.5]

C4 Point symbol: $\left\{4.5^{\wedge} 2\right\}$

Extended point symbol:[4.5(2).5(2)]

C5 Point symbol: $\left\{4.5^{\wedge} 2\right\}$

Extended point symbol:[4.5(2).5(2)]

C6 Point symbol: $\left\{4^{\wedge} 4.5^{\wedge} 16.6^{\wedge} 4.7^{\wedge} 12.8^{\wedge} 9\right\}$

Extended point

symbol:[4.4.4.4.5.5.5.5.5.5.5.5.5.5.5.5.5.5.5.5.6.6.6.6(2).7.7.7.7.7.7.7.7.7.7.7(2).7(2).8.8.8.8(2).8(2).8(2).8(2).8(2).

$8(2)]$

Point symbol for net: $\left\{4.5^{\wedge} 2\right\} 4\left\{4^{\wedge} 4.5^{\wedge} 16.6^{\wedge} 4.7^{\wedge} 12.8^{\wedge} 9\right\}\left\{5^{\wedge} 3\right\}$

3,3,3,3,3,10-c net with stoichiometry (3-c)(3-c)(3-c)(3-c)(3-c)(10-c); 6-nodal net

New topology, please, contact the authors (16813 types in 3 databases)

Elapsed time: $5.11 \mathrm{sec}$. 


\section{Crystal structure analysis of Zr-SXU-2}

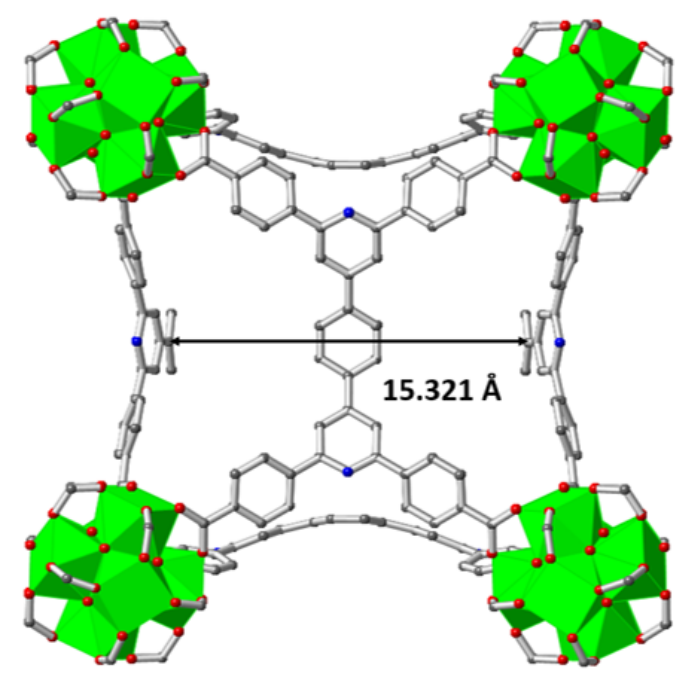

(a)
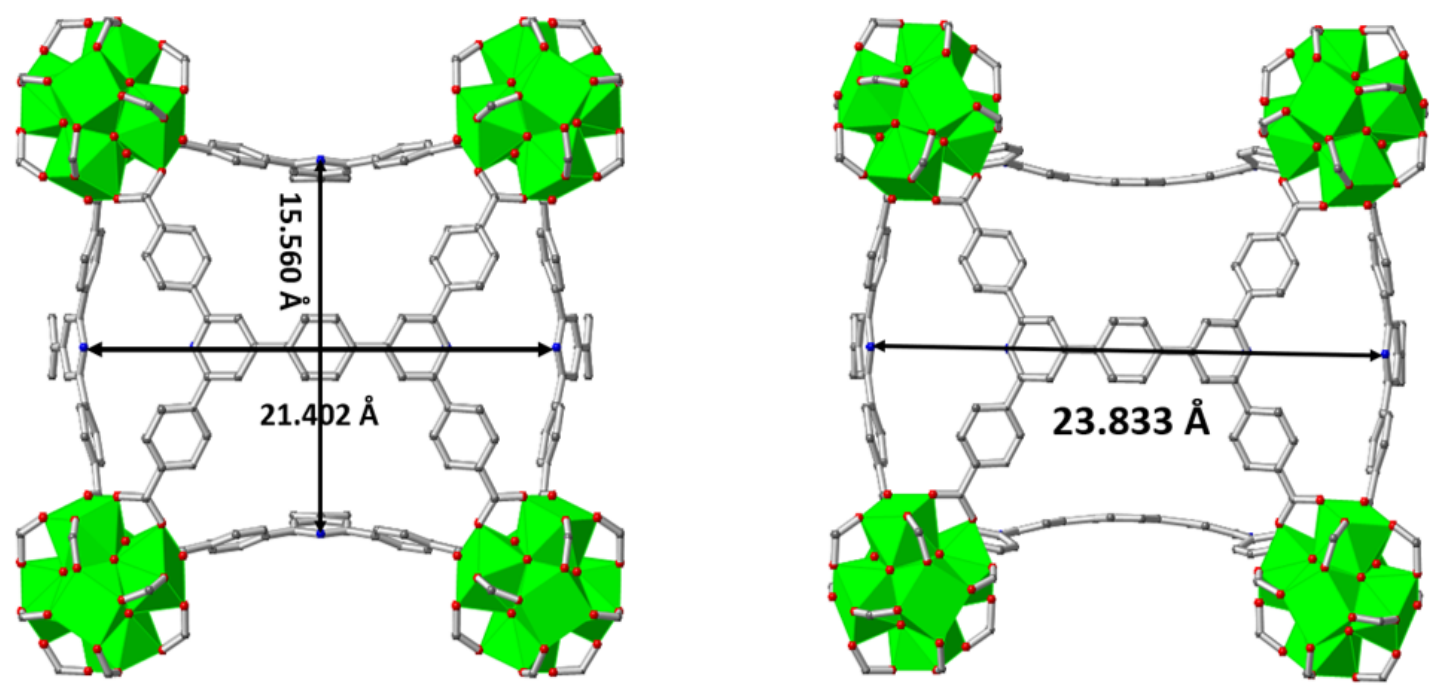

(b)

Figure S3. The size of the cages of Zr-SXU-2. Color code: Zr, green; C, gray; N, blue; O, red. 

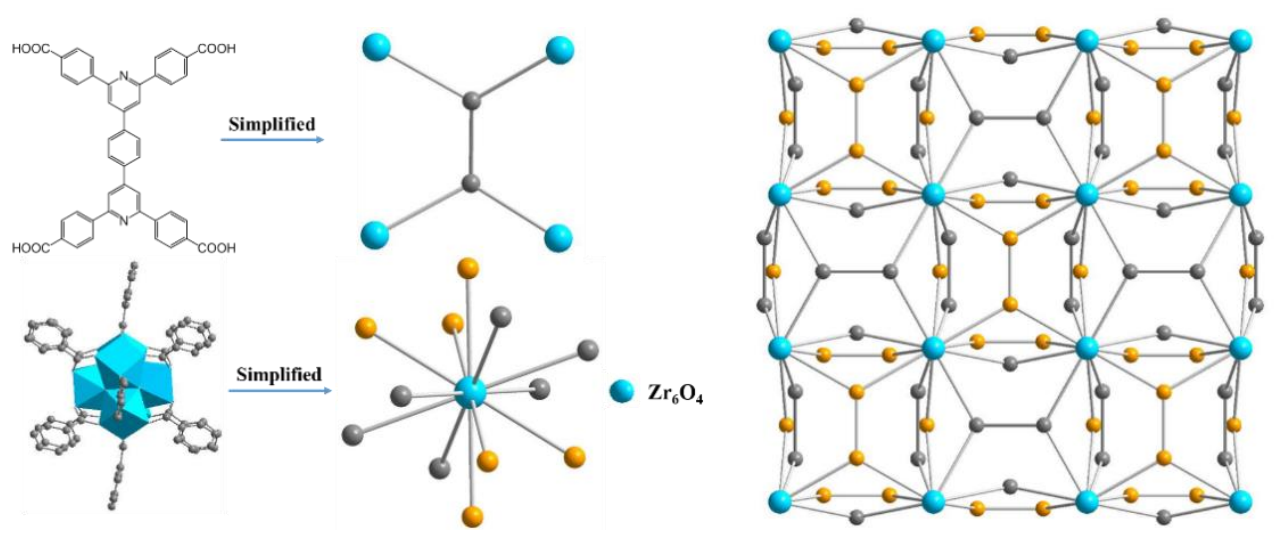

Figure S4. Topological simplification of Zr-SXU-2.

\section{The topological results of $\mathrm{Zr}-\mathrm{SXU}-2$ calculated by ToposPro 5.0}

Coordination sequences

$\begin{array}{lcccccccccc}\mathrm{C} 1: & 1 & 2 & 3 & 4 & 5 & 6 & 7 & 8 & 9 & 10 \\ \text { Num } & 3 & 23 & 40 & 88 & 159 & 211 & 293 & 420 & 500 & 612 \\ \text { Cum } & 4 & 27 & 67 & 155 & 314 & 525 & 818 & 1238 & 1738 & 2350\end{array}$

$\begin{array}{lllllllllll}\mathrm{C} 2: & 1 & 2 & 3 & 4 & 5 & 6 & 7 & 8 & 9 & 10\end{array}$

Num $121860114140234348 \quad 378 \quad 524 \quad 714$

Cum 133191205345579927130518292543

$\begin{array}{lllllllllll}\mathrm{C} 3: & 1 & 2 & 3 & 4 & 5 & 6 & 7 & 8 & 9 & 10\end{array}$

Num $32340 \quad 88159211293 \quad 420 \quad 500 \quad 612$

Cum 42767155314525818123817382350

$\mathrm{TD} 10=2378$

Vertex symbols for selected sublattice

C1 Point symbol: $\left\{4.5^{\wedge} 2\right\}$

Extended point symbol:[4.5(2).5(2)]

C2 Point symbol: $\left\{4^{\wedge} 6.5^{\wedge} 24.6^{\wedge} 6.7^{\wedge} 18.8^{\wedge} 12\right\}$

Extended point

symbol:[4.4.4.4.4.4.5.5.5.5.5.5.5.5.5.5.5.5.5.5.5.5.5.5.5.5.5.5.5.5.6.6.6.6.6.6.7.7.7.7.7.7.7.7.7.7.7.7.7.7.7.7.7.7.8(2).

$8(2) \cdot 8(2) \cdot 8(2) \cdot 8(2) \cdot 8(2) \cdot 8(2) \cdot 8(2) \cdot 8(2) \cdot 8(2) \cdot 8(2) \cdot 8(2)]$

C3 Point symbol: $\left\{4.5^{\wedge} 2\right\}$

Extended point symbol:[4.5(2).5(2)]

Point symbol for net: $\left\{4.5^{\wedge} 2\right\} 6\left\{4^{\wedge} 6.5^{\wedge} 24.6^{\wedge} 6.7^{\wedge} 18.8^{\wedge} 12\right\}$

3,12-c net with stoichiometry (3-c)6(12-c); 2-nodal net 
New topology, please, contact the authors (16813 types in 3 databases)

Elapsed time: $4.21 \mathrm{sec}$.

\section{Crystal structure analysis of Zr-SXU-3}
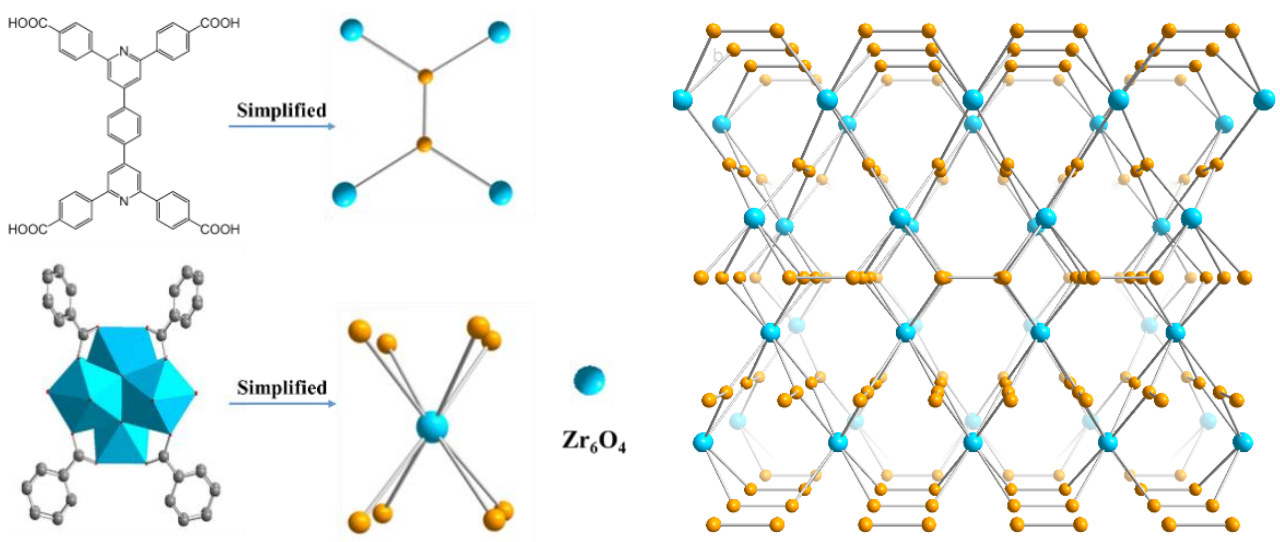

Figure S5. Topological simplification of Zr-SXU-3.

\section{The topological results of $\mathrm{Zr}-\mathrm{SXU}-3$ calculated by ToposPro 5.0}

Coordination sequences

$\begin{array}{lllllllllll}\mathrm{C} 1: & 1 & 2 & 3 & 4 & 5 & 6 & 7 & 8 & 9 & 10\end{array}$

Num $31530 \quad 57111142203299 \quad 332 \quad 455$

Cum 4194910621735956286111931648

C2: $\begin{array}{lllllllllll} & 1 & 2 & 3 & 4 & 5 & 6 & 7 & 8 & 9 & 10\end{array}$

Num $81236 \quad 80 \quad 96160244250 \quad 392 \quad 456$

Cum 9215713723339363788712791735

$\mathrm{TD} 10=1665$

Vertex symbols for selected sublattice

C1 Point symbol: $\left\{4.6^{\wedge} 2\right\}$

Extended point symbol:[4.6.6]

C2 Point symbol: $\left\{4^{\wedge} 4.6^{\wedge} 4.7^{\wedge} 16.9^{\wedge} 4\right\}$

Extended point

symbol:[4.4.4.4.6.6.6.6.7(2).7(2).7(2).7(2).7(2).7(2).7(2).7(2).7(2).7(2).7(2).7(2).7(4).7(4).7(4).7(4).9(4).9(4).9( 4).9(4)]

Point symbol for net: $\left\{4.6^{\wedge} 2\right\} 4\left\{4^{\wedge} 4.6^{\wedge} 4.7^{\wedge} 16.9^{\wedge} 4\right\}$

3,8-c net with stoichiometry (3-c)4(8-c); 2-nodal net 
Topological type: sqc3782 (epinet.ttd) $\left\{4.6^{\wedge} 2\right\} 4\left\{4^{\wedge} 4.6^{\wedge} 4.7^{\wedge} 16.9^{\wedge} 4\right\}-$ VS [4.6.6]

[4.4.4.4.6.6.6.6.7(2).7(2).7(2).7(2).7(2).7(2).7(2).7(2).7(2).7(2).7(2).7(2).7(4).7(4).7(4).7(4).*.**.*] (16813

types in 3 databases)

Please contact the EPINET database for details: http://epinet.anu.edu.au/sqc3782

Elapsed time: $3.41 \mathrm{sec}$.

Table S1. Summary of the Crystal Data and Structure Refinement Parameters

\begin{tabular}{|c|c|c|c|}
\hline Identification code & Zr-SXU-1 & Zr-SXU-2 & Zr-SXU-3 \\
\hline $\mathrm{CCDC}$ & 1962441 & 1962462 & 1962442 \\
\hline Formula & \multicolumn{2}{|l|}{$\mathrm{C}_{129.33} \mathrm{H}_{66.67} \mathrm{~N}_{6} \mathrm{O}_{42.67} \mathrm{Zr}_{8}$} & $\mathrm{C}_{58.53} \mathrm{H}_{31.26} \mathrm{~N}_{2.66} \mathrm{O}_{17.32} \mathrm{Zr}_{3}$ \\
\hline Formula weight & \multicolumn{2}{|l|}{3116.98} & 1322.55 \\
\hline Temperature/K & \multicolumn{2}{|l|}{100} & 293(2) \\
\hline Crystal system & \multicolumn{2}{|l|}{ trigonal } & tetragonal \\
\hline Space group & \multicolumn{2}{|l|}{ P-3m1 } & I41/amd \\
\hline $\mathrm{a} / \AA ̊$ & $54.430(8)$ & 39.393 & $20.6671(4)$ \\
\hline $\mathrm{b} / \AA$ & $54.430(8)$ & 39.393 & $20.6671(4)$ \\
\hline $\mathrm{c} / \AA$ & $39.530(8)$ & 39.393 & $66.879(2)$ \\
\hline$\alpha /{ }^{\circ}$ & 90 & 90 & 90.0 \\
\hline$\beta /{ }^{\circ}$ & 90 & 90 & 90.0 \\
\hline$\gamma^{\circ}$ & 120 & 90 & 90.0 \\
\hline Volume $/ \AA^{3}$ & $101422(35)$ & 61130 & $28565.8(15)$ \\
\hline Z & 9 & & 8 \\
\hline$\rho_{\text {calc }} \mathrm{g} / \mathrm{cm}^{3}$ & 0.459 & & 0.615 \\
\hline$\mu / \mathrm{mm}^{-1}$ & 0.921 & & 0.244 \\
\hline $\mathrm{F}(000)$ & 13914.0 & & 5277.0 \\
\hline Crystal size $/ \mathrm{mm}^{3}$ & $0.05 \times 0.03 \times 0.03$ & & $0.3 \times 0.3 \times 0.1$ \\
\hline Radiation & Synchrotron $(\lambda=0.65247)$ & & $\operatorname{MoK} \alpha(\lambda=0.71073)$ \\
\hline Reflections collected & 113794 & & 47247 \\
\hline \multirow{2}{*}{ Independent reflections } & \multicolumn{2}{|l|}{$58893\left[\mathrm{R}_{\text {int }}=0.2682, \mathrm{R}_{\text {sigma }}=\right.$} & $9391\left[R_{\text {int }}=0.1255\right.$ \\
\hline & \multicolumn{2}{|l|}{$0.3068]$} & $\left.\mathrm{R}_{\text {sigma }}=0.1459\right]$ \\
\hline Goodness-of-fit on $\mathrm{F}^{2}$ & \multicolumn{2}{|l|}{0.968} & 0.954 \\
\hline
\end{tabular}


Final $\mathrm{R}$ indexes $\left[\mathrm{I}>=2 \sigma \quad \mathrm{R}_{1}=0.1054\right.$,

(I)] $\quad \mathrm{wR}_{2}=0.2728$

Final $\mathrm{R}$ indexes [all $\mathrm{R}_{1}=0.2213$,

data]
$\mathrm{R}_{1}=0.0707$

$\mathrm{wR}_{2}=0.1789$

$\mathrm{R}_{1}=0.1502$,

$\mathrm{wR}_{2}=0.2146$

$R_{1}=\Sigma|| F_{\mathrm{o}}|-| F_{\mathrm{c}}|| / \Sigma\left|F_{\mathrm{o}}\right| .{ }^{\mathrm{b}} w R_{2}=\left[\sum\left[w\left(F_{\mathrm{o}}{ }^{2}-F_{\mathrm{c}}{ }^{2}\right)^{2}\right] / \Sigma\left[w\left(F_{\mathrm{o}}{ }^{2}\right)^{2}\right]\right]^{1 / 2}$

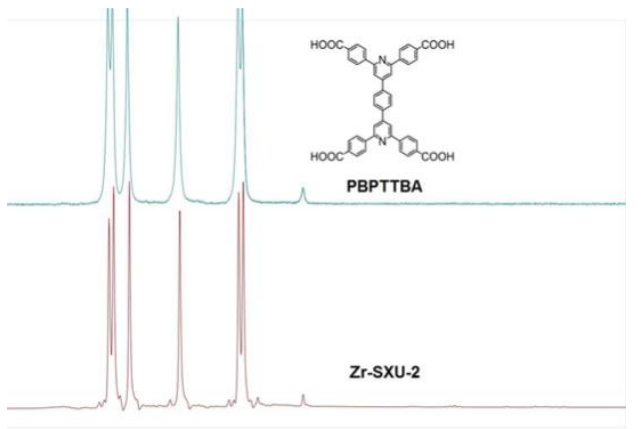

$\begin{array}{lllllllllllllllllll}8.8 & 8.7 & 8.6 & 8.5 & 8.4 & 8.3 & 8.2 & 8.1 & 8.0 & 7.9 & 7.8 & 7.7 & 7.6 & 7.5 & 7.4 & 7.3 & 7.2 & 7.1 & 7\end{array}$

(a)

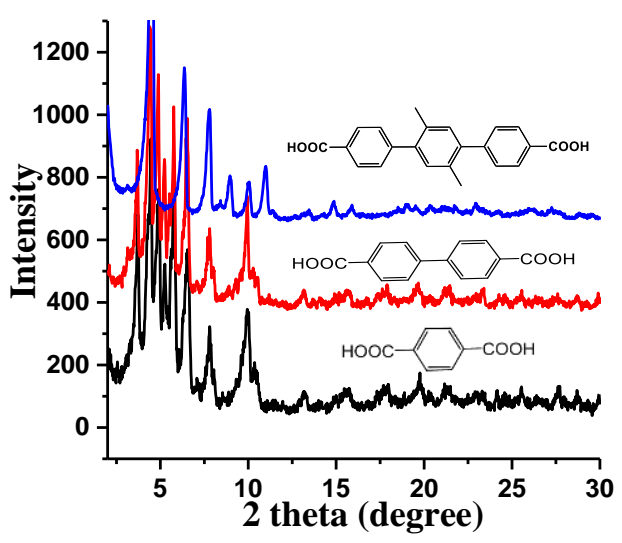

(b)

Figure S6. (a) ${ }^{1} \mathrm{H}-\mathrm{NMR}$ of the acid rinsed Zr-SXU-2 and PBPTTBA; (b) PXRD patterns of materials obtained through different ditopic carboxylic acid as the modulators. 


\section{Gas Sorption measurement}
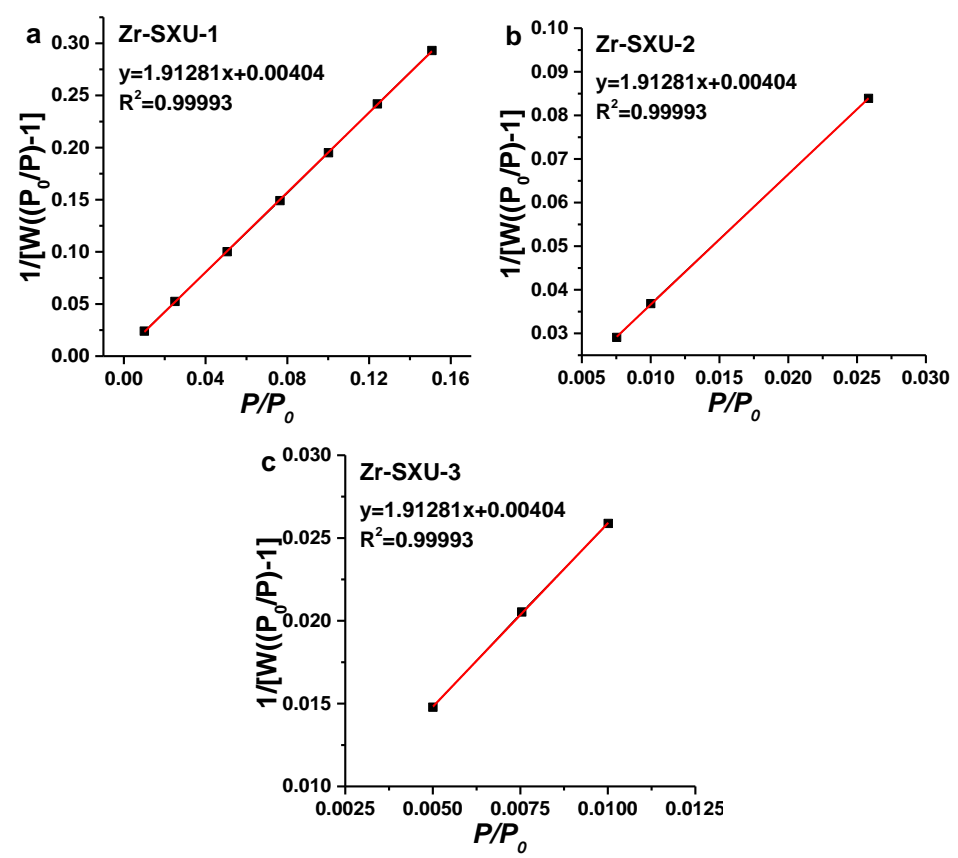

Figure S7. Plot of $1 /\left[\mathrm{W}\left(\left(\mathrm{P}_{0} / \mathrm{P}\right)-1\right)\right]$ vs. $P / P_{0}$ to determine the BET surface area.

Table S2. Adsorption amount of three kinds of complexes for different gases

$273 \mathrm{~K}$

\begin{tabular}{ccccc}
\hline & $\mathrm{C}_{2} \mathrm{H}_{2}\left(\mathrm{~cm}^{3} \mathrm{~g}^{-1}\right)$ & $\mathrm{C}_{2} \mathrm{H}_{4}\left(\mathrm{~cm}^{3} \mathrm{~g}^{-1}\right)$ & $\mathrm{CO}_{2}\left(\mathrm{~cm}^{3} \mathrm{~g}^{-1}\right)$ & $\mathrm{CH}_{4}\left(\mathrm{~cm}^{3} \mathrm{~g}^{-1}\right)$ \\
\hline Zr-SXU-1 & 73.3544 & 64.6869 & 42.4427 & 11.6596 \\
Zr-SXU-2 & 55.4735 & 46.9541 & 34.5691 & 10.8371 \\
Zr-SXU-3 & 82.2995 & 69.2511 & 44.2946 & 12.8556 \\
\hline
\end{tabular}
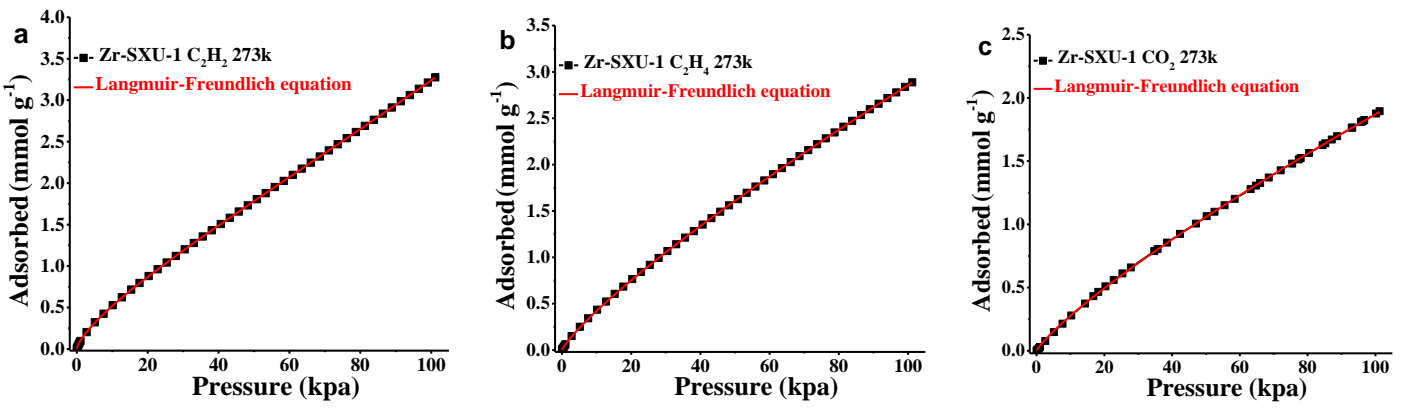

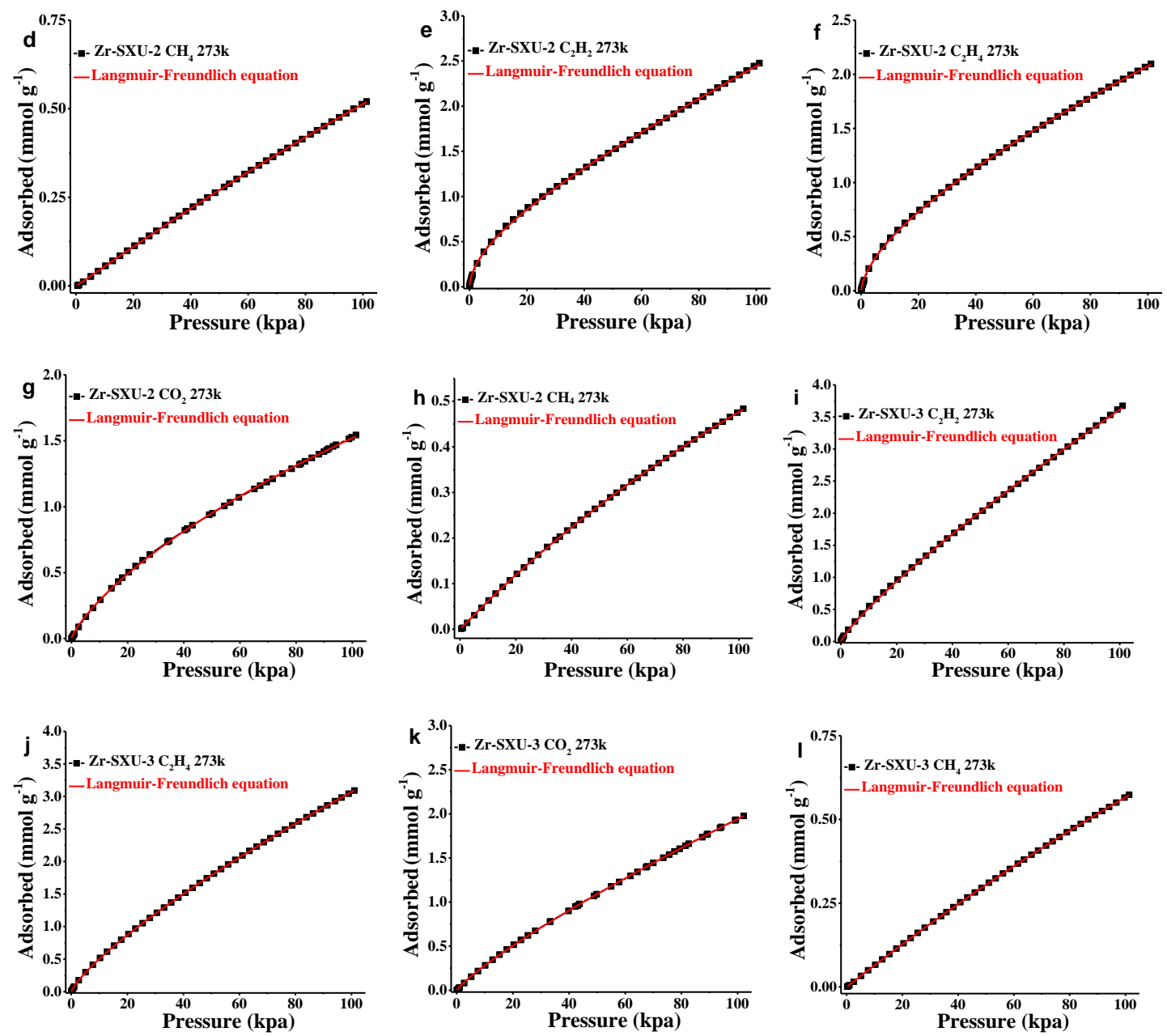

Figure S8. $\mathrm{C}_{2} \mathrm{H}_{2}, \mathrm{C}_{2} \mathrm{H}_{4}, \mathrm{CO}_{2}$, and $\mathrm{CH}_{4}$ adsorption isotherms of $\mathrm{Zr}-\mathrm{SXU}-1, \mathrm{Zr}-\mathrm{SXU}-2$ and $\mathrm{Zr}-\mathrm{SXU}-3$ with fitting by

Single-site Langmuir-Freundlich model.
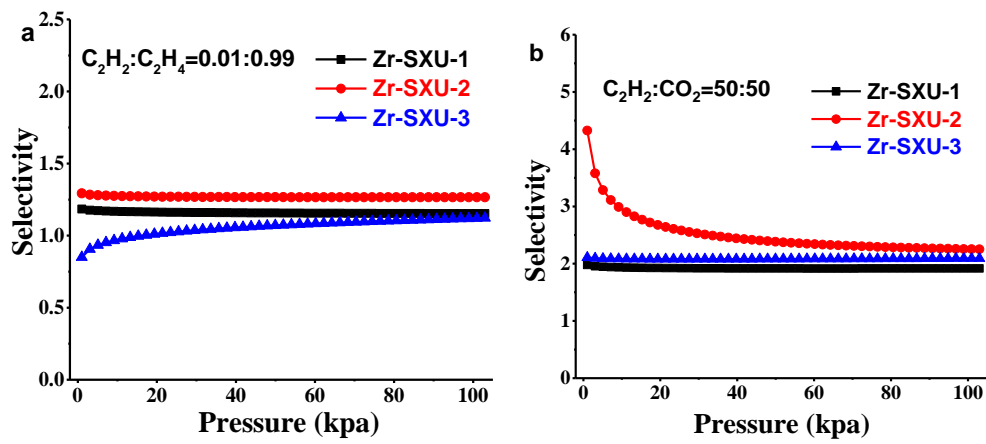


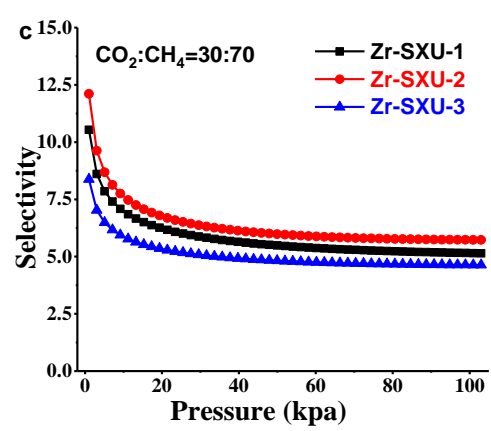

Figure S9. IAST selectivity of $\mathrm{C}_{2} \mathrm{H}_{2} / \mathrm{C}_{2} \mathrm{H}_{4}(1 / 99 \mathrm{v} / \mathrm{v}), \mathrm{C}_{2} \mathrm{H}_{2} / \mathrm{CO}_{2}(50 / 50 \mathrm{v} / \mathrm{v})$ and $\mathrm{CO}_{2} / \mathrm{CH}_{4}(30 / 70 \mathrm{v} / \mathrm{v})$ at $273 \mathrm{~K}$ in Zr-SXU-1, Zr-SXU-2 and Zr-SXU-3.

To remove all the guest solvents in the framework, the fresh as-synthesized sample of Zr-SXU1, Zr-SXU-2 and Zr-SXU-3 were guest-exchanged with $\mathrm{CH}_{2} \mathrm{Cl}_{2}$ at least 8 times. These samples were degassed at $150{ }^{\circ} \mathrm{C}$ for $12 \mathrm{~h} . \mathrm{C}_{2} \mathrm{H}_{2}, \mathrm{C}_{2} \mathrm{H}_{4}, \mathrm{CO}_{2}$, and $\mathrm{CH}_{4}$ adsorption isotherms were collected on Quantachrome autosorb iQ2 automated gas sorption analyzer for the guest-free sample.

The pure component isotherm data for $\mathrm{C}_{2} \mathrm{H}_{2}, \mathrm{C}_{2} \mathrm{H}_{4}, \mathrm{CO}_{2}$, and $\mathrm{CH}_{4}$, measured at $273 \mathrm{~K}$ were fitted with the Single-site Langmuir-Freundlich isotherm model:

$$
q=q_{m} \frac{b p^{1 / t}}{1+b p^{1 / t}}
$$

where $p$ (unit: $\mathrm{kPa}$ ) is the pressure of the bulk gas when in equilibrium with the adsorbed phase, $q$ (unit: $\mathrm{mmol} / \mathrm{g}$ ) is the adsorbed amount per mass of adsorbent, $\mathrm{q}_{\mathrm{m}}$ (unit: $\mathrm{mmol} / \mathrm{g}$ ) is the saturation loadings, $\mathrm{b}$ (unit: $1 / \mathrm{kPa}$ ) are the affinity coefficient, $\mathrm{t}$ represents the deviations from an ideal homogeneous surface. The fitting parameters of the Single-site Langmuir-Freundlich equation for $\mathrm{C}_{2} \mathrm{H}_{2}, \mathrm{C}_{2} \mathrm{H}_{4}, \mathrm{CO}_{2}$, and $\mathrm{CH}_{4}$ are listed in Table S2.

Table S3. The obtained Single-site Langmuir fitting parameters

\begin{tabular}{lllll}
\hline & & Zr-SXU-1 & Zr-SXU-2 & Zr-SXU-3 \\
\hline & $\mathrm{b}$ & $4.03731 \times 10^{-4}$ & $1.50684 \times 10^{-4}$ & $2.6317 \times 10^{-4}$ \\
$\mathrm{C}_{2} \mathrm{H}_{2}$ & $\mathrm{t}$ & 1.20093 & 1.5323 & 1.18189 \\
& $\mathrm{q}$ & 173.97761 & 794.74943 & 282.61476 \\
& $\mathrm{R}^{2}$ & 1 & 0.99913 & 0.99986 \\
& $\mathrm{~b}$ & $4.03573 \times 10^{-4}$ & $9.61617 \times 10^{-4}$ & $8.09535 \times 10^{-4}$ \\
$\mathrm{C}_{2} \mathrm{H}_{4}$ & $\mathrm{t}$ & 1.19348 & 1.52126 & 1.25392 \\
& $\mathrm{q}$ & 152.11985 & 106.10234 & 99.39912 \\
\hline
\end{tabular}




\begin{tabular}{lllll}
\hline & $\mathrm{R}^{2}$ & 1 & 1 & 0.99999 \\
& $\mathrm{~b}$ & $7.02581 \times 10^{-4}$ & 0.00578 & $6.24314 \times 10^{-4}$ \\
$\mathrm{CO}_{2}$ & $\mathrm{t}$ & 1.18826 & 1.26764 & 1.17501 \\
& $\mathrm{q}$ & 57.0838 & 8.47776 & 63.6643 \\
& $\mathrm{R}$ & 0.99992 & 0.99981 & 0.99996 \\
$\mathrm{CH}_{4}$ & $\mathrm{R}$ & 0.00137 & 0.00321 & 0.00174 \\
& $\mathrm{~b}$ & 0.97557 & 1.00632 & 0.9914 \\
& $\mathrm{q}$ & 3.846 & 2.0029 & 3.70108 \\
& $\mathrm{q}$ & 0.99997 & 0.99995 & 0.99999 \\
\hline
\end{tabular}

Adsorption selectivities were established by IAST for mixed $\mathrm{C}_{2} \mathrm{H}_{2} / \mathrm{C}_{2} \mathrm{H}_{4}(1 / 99 \mathrm{v} / \mathrm{v}), \mathrm{C}_{2} \mathrm{H}_{2} / \mathrm{CH}_{4}$ $(50 / 50 \mathrm{v} / \mathrm{v}), \mathrm{C}_{2} \mathrm{H}_{2} / \mathrm{CO}_{2}(50 / 50 \mathrm{v} / \mathrm{v})$ and $\mathrm{CO}_{2} / \mathrm{CH}_{4}(30 / 70 \mathrm{v} / \mathrm{v})$ in the $\mathrm{Zr}-\mathrm{SXU}-1, \mathrm{Zr}-\mathrm{SXU}-2$ and $\mathrm{Zr}-$ SXU-3. The selectivity of preferential adsorption of component 1 over component 2 in a mixture containing 1 and 2 , can be formally defined as:

$$
S_{a d s}=\frac{q_{1} / q_{2}}{p_{1} / p_{2}}
$$

In the above equation, $q 1$ and $q 2$ are the equilibrated adsorption capacity of component 1 and 2 respectively, and $p 1$ and $p 2$ are the molar fractions of component 1 and 2 in gas phased respectively. We calculate the values of $q 1$ and $q 2$ using the Ideal Adsorbed Solution Theory (IAST) of Myers and Prausnitz.

Table S4. The amount of $\mathrm{N}$ atoms in Zr-SXU-1, Zr-SXU-2 and Zr-SXU-3

\begin{tabular}{l|l|l|l}
\hline & $\mathrm{Zr}-\mathrm{SXU}-1$ & $\mathrm{Zr}-\mathrm{SXU}-2$ & $\mathrm{Zr}-\mathrm{SXU}-3$ \\
\hline Formula & $\mathrm{Zr}_{6} \mathrm{O}_{4}(\mathrm{OH})_{4}\left(\mathrm{H}_{2} \mathrm{O}\right)_{4} \mathrm{~L}_{2.5}$ & $\mathrm{Zr}_{6} \mathrm{O}_{4}(\mathrm{OH})_{4} \mathrm{~L}_{3}$ & $\mathrm{Zr}_{6} \mathrm{O}_{4}(\mathrm{OH})_{8}\left(\mathrm{H}_{2} \mathrm{O}\right)_{4} \mathrm{~L}_{7 / 3}$ \\
\hline $\mathrm{N}$ & 5 & 6 & 4.67 \\
\hline
\end{tabular}




\section{Fluorescence Measurements}
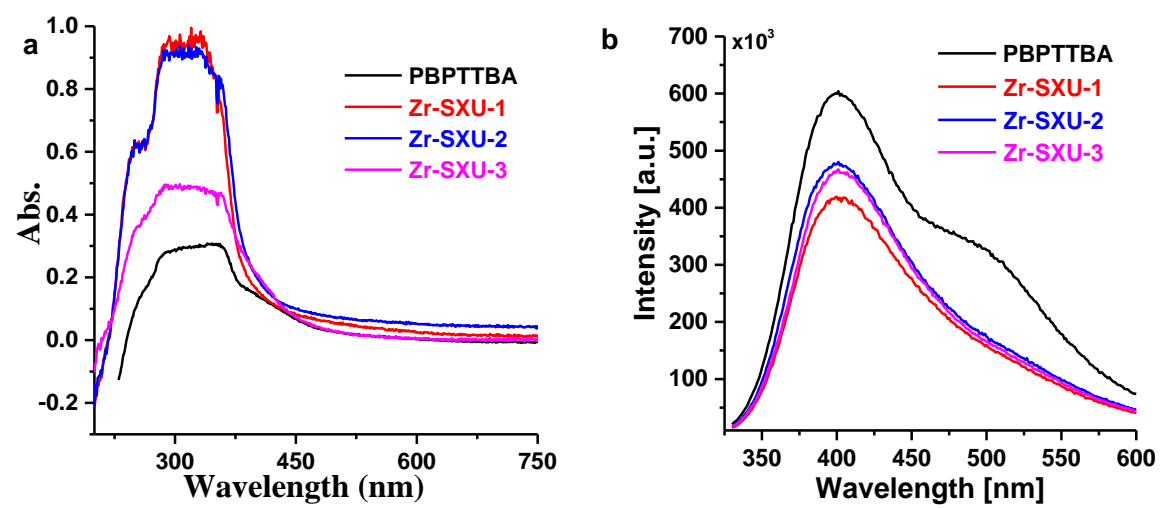

Figure S10. (a) The diffuse reflectance ultraviolet-visible (DR UV-vis) spectra of solid samples of Zr-SXU-1, Zr-

SXU-2, Zr-SXU-3 and PBPTTBA. (b) Solid-state fluorescent spectra of Zr-SXU-1, Zr-SXU-2 and free PBPTTBA under excitation of $320 \mathrm{~nm}$ at room temperature, and of Zr-SXU-3 under excitation of $310 \mathrm{~nm}$ at room temperature.

The powder sample of Zr-SXU-1 (10 mg), Zr-SXU-2 (10 mg) or Zr-SXU-3 (10 mg) was immersed in $30 \mathrm{~mL}$ of deionized water and ultrasonicated for $3 \mathrm{~h}$ to form a stable turbid suspension; then $1 \mathrm{~mL}$ of it was added to a cuvette containing $1 \mathrm{~mL}$ of different concentrations aqueous solution of metal ion $\mathrm{Fe}^{3+}$.

As is well-known, the fluorescent quenching efficiency can be quantitatively explained by the Stern-Volmer (SV) equation: $\left(\mathrm{I}_{0} / \mathrm{I}\right)=1+\mathrm{K}_{\mathrm{sv}}[\mathrm{M}]$, where $\mathrm{I}_{0}$ and $\mathrm{I}$ are the fluorescent intensities of MOF and MOF-Fe ${ }^{3+}$ suspensions, respectively; $[\mathrm{M}]$ represents the molar concentration of $\mathrm{Fe}^{3+}$ ions $(\mu \mathrm{M})$; and $\mathrm{K}_{\mathrm{sv}}$ is the SV constant $\left(\mathrm{M}^{-1}\right)$. Based on the $\mathrm{K}_{\mathrm{sv}}$ values and the standard deviations $\left(\mathrm{S}_{\mathrm{b}}\right)$ from three repeated fluorescent measurements of blank solutions, the detection limits $\left(3 \mathrm{~S}_{\mathrm{b}} / \mathrm{K}_{\mathrm{sv}}\right)$ of Zr-SXU-1, Zr-SXU-2 and Zr-SXU-3 toward Fe ${ }^{3+}$ ion in water were calculated to be $0.176,0.214$ and $0.128 \mu \mathrm{M}$, respectively. 


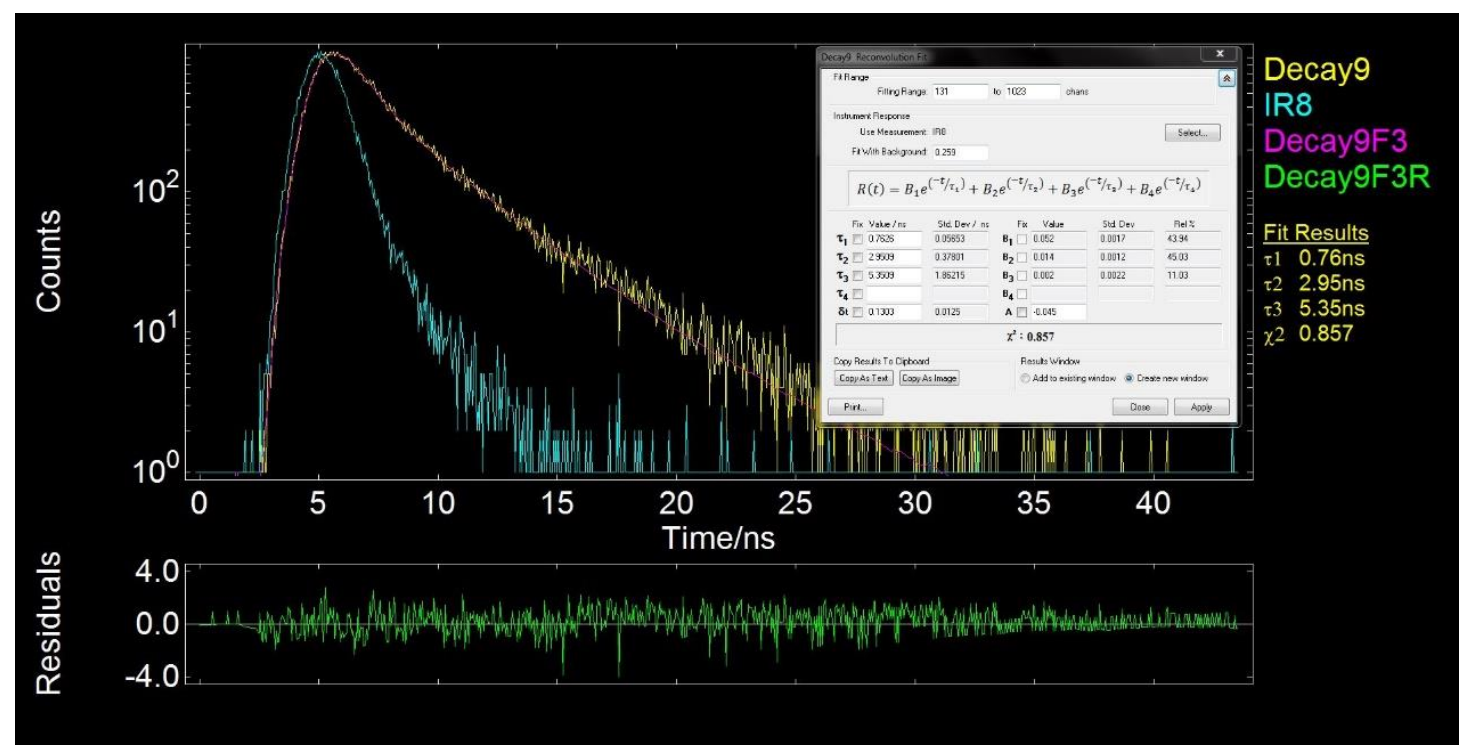

(a)

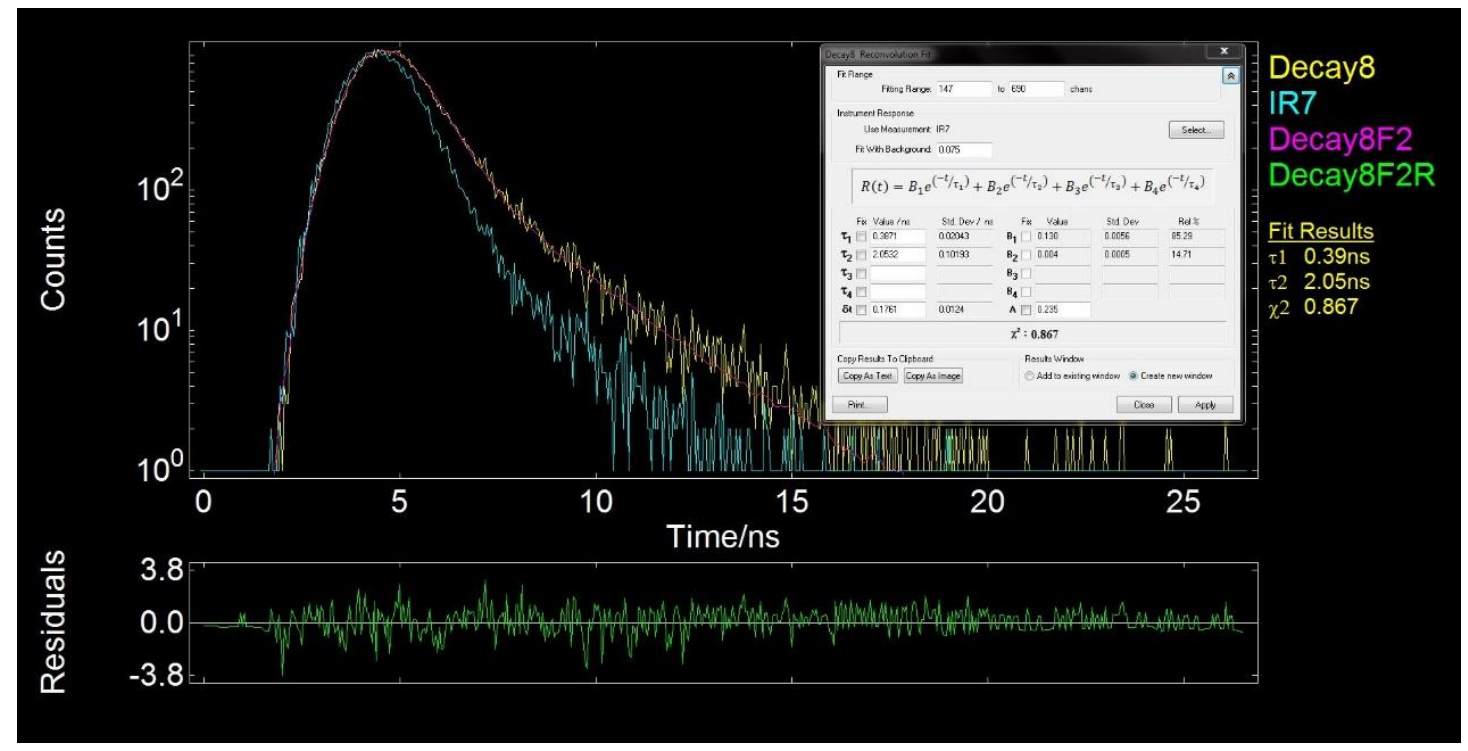

(b)

Fig. S11. Life time of Zr-SXU-1 before (a) and after addition of Fe ${ }^{3+}$ ions (Ex: 320 nm, Em: 380 nm). 


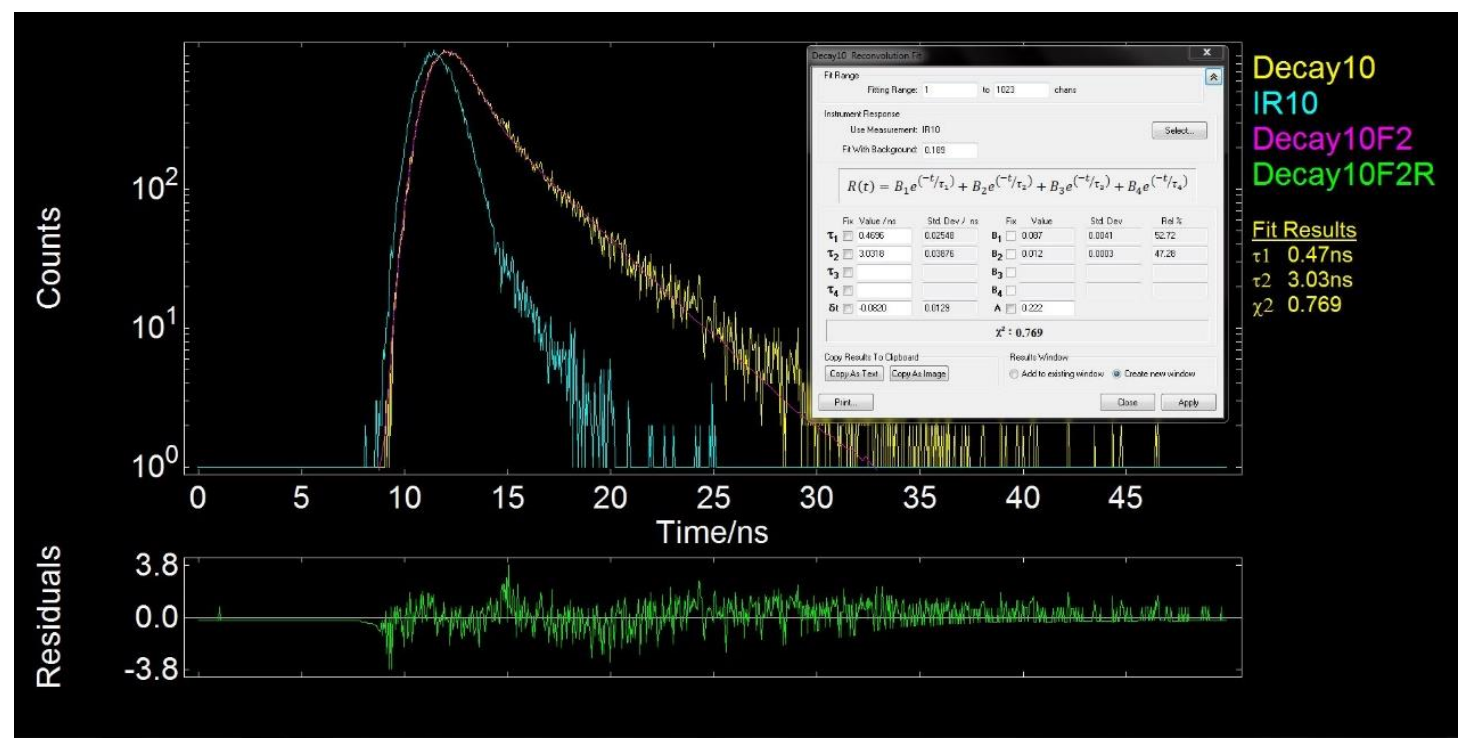

(a)

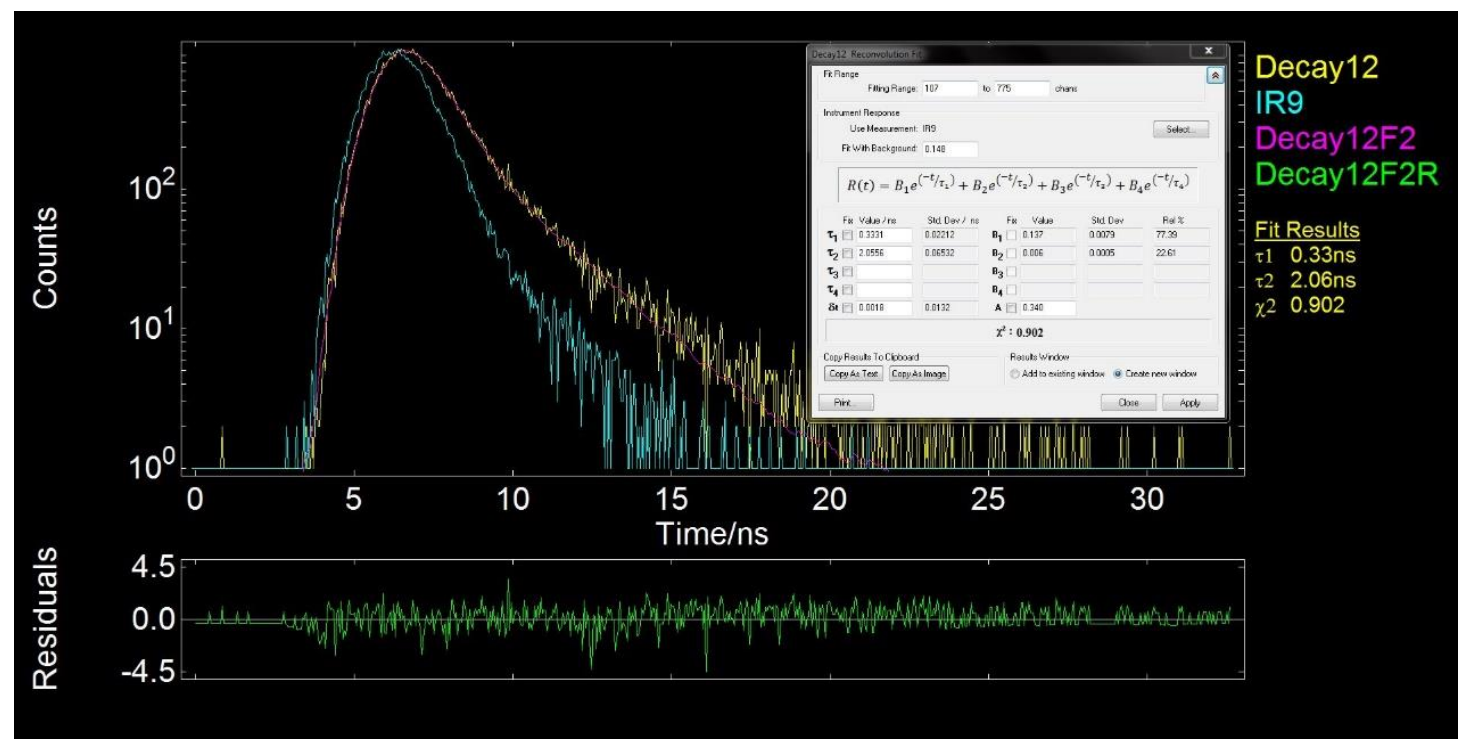

(b)

Fig. S12. Life time of Zr-SXU-2 before (a) and after addition of Fe ${ }^{3+}$ ions (Ex: 320 nm, Em: $380 \mathrm{~nm}$ ).

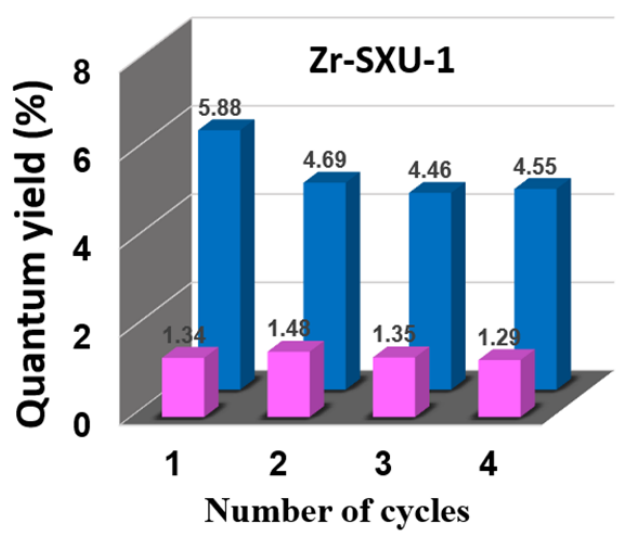

(a)

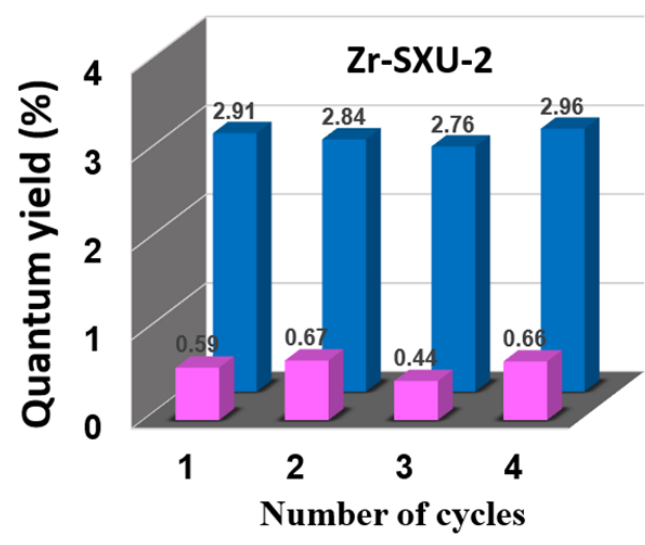

(b) 
Fig. S13. Cyclic tests of Zr-SXU-1 and Zr-SXU-2 for sensing of Fe ${ }^{3+}$ ions. 